\title{
AVALIAÇÃO DE ÓLEOS ESSENCIAIS DE ORÉGANO E ALECRIM NA PREVENÇÃO DA DIARREIA NEONATAL EM LEITÕES
}

\author{
F.C. Luchese, M. Cecim, M. Soares
}

Universidade Federal de Santa Maria, Centro de Ciências Rurais, Departamento de Clínica de Grandes Animais, Setor de Clínica de Ruminantes, Avenida Roraima, 1000, CEP 97105-900, Santa Maria, RS, Brasil. E-mail:franvety@yahoo.com.br

\section{RESUMO}

\begin{abstract}
Com objetivo de verificar o efeito preventivo da emulsão líquida de uma mescla de óleos essenciais de orégano (Origanum vulgare) e alecrim (Rosmarinus officinalis) no controle da diarreia neonatal em leitões lactantes foi realizado um experimento composto por dois tratamentos simples em um delineamento experimental inteiramente casualizado. Leitões de mesma leitegada, nascidos de fêmeas com ordens de partos variadas, foram divididos em 2 grupos de leitões sem manifestação clínica de diarreia neonatal. O primeiro grupo com 661 leitões recebeu o tratamento controle ( $1 \mathrm{~mL} \mathrm{~kg}^{-1}$ solução fisiológica) e o segundo grupo com 672 animais recebeu óleos essenciais de orégano (60\% de carvacrol e 15\% timol) e $2 \%$ de óleo essencial de alecrim, sob a forma de emulsão líquida a $5 \%$ na dose de $1 \mathrm{~mL} \mathrm{~kg}^{-1}$. Todos os tratamentos foram administrados via oral no primeiro e terceiro dias de vida do suíno, sendo que, para o parâmetro índice de prevenção e causas de mortalidade dos leitões, cada animal representou uma repetição. Não houve diferença significativa entre os tratamentos quanto ao índice de prevenção da diarreia neonatal em leitões. Os resultados permitiram concluir que a mescla de óleos essenciais à base de orégano e alecrim não previne as diarreias neonatais dos leitões.
\end{abstract}

PALAVRAS-CHAVE: Extratos vegetais, suínos, enterites, Origanum vulgare, Rosmarinus officinalis.

\begin{abstract}
EVALUATION OF OREGANO AND ROSEMARY ESSENTIAL OILS FOR THE PREVENTION OF NEONATAL DIARRHEA IN PIGLETS. In order to verify the preventive effect of the liquid emulsion of a mix of essential oils of oregano (Origanum vulgare) and rosemary (Rosmarinus officinalis) in the control of neonatal diarrhea in nursing piglets, an experiment was conducted using a randomized experimental design composed by two simple treatments. Piglets from the same litter, born to females with different orders of births, were divided into two groups of piglets without clinical signs of neonatal diarrhea. The first group of 661 pigs received the control treatment ( $1 \mathrm{~mL} \mathrm{~kg}^{-1}$ saline) while the second group with 672 animals received essential oils of oregano $(60 \%$ carvacrol and $15 \%$ thymol) and $2 \%$ essential oil of rosemary in the form of a $5 \%$ liquid emulsion at a dose of $1 \mathrm{~mL} \mathrm{~kg}^{-1}$. All the treatments were administered orally on the first and third day of the piglets' life, and in regard to the index parameter for the prevention and causes of mortality of piglets, each animal represented a repetition. There was no significant difference between the treatments related to the rate of prevention of neonatal diarrhea in piglets. The results showed that the mix of essential oils from oregano and rosemary do not prevent diarrhea in neonatal piglets.
\end{abstract}

KEY WORDS: Plant extracts, pigs, enteritis, Origanum vulgare, Rosmarinus officinalis.

\section{INTRODUÇÃO}

A diarreia é o principal evento clínico observado no período neonatal em leitões e constitui uma das mais importantes causas de mortalidade em leitões na maternidade e após o desmame (ANAMi et al., 2008).

As causas de diarreia em leitões são multifatoriais ea simples presença de enteropatógenos nem sempre é suficiente para o desenvolvimento da doença. A morbidade e a mortalidade dependem da virulência do agente, da resistência do hospedeiro e da presença de fatores de risco, tais como a temperatura ambiente, higiene inadequada das instalações e dificuldade de acesso ao colostro e ao leite (DEWEY et al., 1995; FIREMAN; SIEWERDT, 1997).

A incidência de diarreias neonatais em leitões na maternidadeapresenta importância pelo seu impacto econômico devido à alta mortalidade, atraso no desenvolvimento, bem como uma pior conversão alimentar e aumento dos custos com medicamentos 
(Holland, 1990; Brito et al., 1995). Leitões provenientes de leitegadas com diarreia pesaram cerca de $0,4 \mathrm{~kg}$ a menos aos 30 dias de idade que leitões oriundos de leitegadas sem diarreia (MARTINEAU et al., 1995). Os mais frequentes agentes responsáveis pelas enterites durante o período pré-desmame são a Escherichia coli enterotoxigênica, a Isospora suis, o rotavírus e o Clostridium perfringens tipo $\mathrm{C}$ ou A (KATSUDA et al., 2006).

O segmento recorre regularmente ao uso constante de vários antimicrobianos em doses subclínicas de consumo desses produtos, constituindo um risco à saúde pública pelo efeito da resistência microbiana (BELLAVER, 2000).

Diante deste quadro a União Europeia passou a adotar medidas restritivas às importações de carne e produtos derivados, o que têm forçado a busca de alternativas que garantam o mesmo desempenho animal sem afetar a qualidade do produto final e sem o risco de resíduos indesejáveis à saúde do consumidor (DematTê, 2004).

Os probióticos e prebióticos têm sido testados em dietas para suínos recém-desmamados como potenciais alternativas aos antibióticos e quimioterápicos como promotores do crescimento. Os probióticos podem atuar por diferentes mecanismos: exclusão competitiva e antagonismo direto (MENTEN, 2001) e supressão da produção de amônia e neutralização de enterotoxinas (Jin et al.,1997). Os prebióticos, por sua vez, podem aderir a certos patógenos evitando sua adesão e colonização no epitélio intestinal (MACARI; MAIORKA, 2000).

Por outro lado, os óleos essenciais ainda são pouco estudados, mas têm sido realizadas pesquisas utilizando-os na prevenção das diarreias dos leitões na primeira semana de vida. Quimicamente classificam-se como misturas complexas de substâncias voláteis, geralmente lipofílicas (SIMÕES et al., 1999), cujos componentes incluem hidrocarbonetos terpênicos, alcoóis simples, aldeídos, cetonas, fenóis, ésteres, ácidos orgânicos, em diferentes concentrações, onde um composto farmacologicamente ativo é majoritário (KAMEL, 2000).

São vários os efeitos observados in vitro que justificam as pesquisas para determinação das melhores combinações e dos níveis de inclusão dos óleos essenciais às dietas ou no desenvolvimento de antimicrobianos naturais de uso oral para melhorar o desempenho e a produção animal (HERNÁNDEZ et al., 2004). Estas substâncias estimulam a digestão, alteram a microbiota intestinal (efeito antimicrobiano), melhoram a digestibilidade e a absorção dos nutrientes, melhorando a resposta imuneeinduzindo modificações morfo-histológicas do trato gastrintestinal (Mellor, 2000; BRUgaLLI, 2003).

Considerando-se que as enterites causam sérios prejuízos econômicos, este trabalho se propõe a avaliar a eficiência da administração da solução de óleos essenciais de orégano e alecrim, a 5\%, administrada via oral (pigdoser) em leitões lactantes, no período entre o nascimento e o sétimo dia de vida, na prevenção da diarreia neonatal dos leitões.

\section{MATERIAL E MÉTODOS}

\section{Animais e instalações experimentais}

O trabalho foi realizado com leitões provenientes de 112 fêmeas suínas (Large White $x$ Landrace) de diferentes idades reprodutivas que não foram vacinadas contra colibacilose e clostridiose.

As instalações foram previamentelavadas, desinfetadas (amônia quaternária), fechadas e mantidas em vazio sanitário previamente ao alojamento dos animais. Estas instalações foram construídas no sentido Leste-Oeste, sem lanternin, pé direito de 3 m de altura, laterais abertas com muretas de $0,75 \mathrm{~cm}$, beirais longos $(1,40 \mathrm{~m})$, e com cobertura de telhas de fibro-cimento pintadas externamente com tinta refletiva. O galpão possuía cortinas de polietileno com dispositivos de controle de abertura lateral, com movimentos de baixo para cima e vice-versa, sendo geralmente abertas às $7 \mathrm{~h} 30 \mathrm{~min}$ e fechadas em torno de 18h. Os seis ventiladores de $1.730 \mathrm{rpm}$ (modelo NBR - 7094), localizados internamente nas laterais da sala a uma altura de $2 \mathrm{~m}$ do piso, eram acionados, rotineiramente, das 11 até as $16 \mathrm{~h}$. As matrizes e seus respectivos leitões mantiveram-se juntos em celas individuais dotadas de escamoteadores providos de aquecimento com lâmpada de 100 watts, bebedouro tipo chupeta e comedouros específicos e separados para as fêmeas e para os leitões.

Durante a gestação todas as fêmeas receberam o mesmo manejo alimentar até o $107^{\circ} \mathrm{e} /$ ou $110^{\circ}$ dia de gestação, distribuído da seguinte forma:

Ração de Gestação: $2,5 \mathrm{~kg}$ de ração por dia da cobertura ate o $30^{\circ}$ dia e $2,6 \mathrm{~kg}$ de ração por dia do $31^{\circ}$ ao $85^{\circ}$ dia de gestação. A ração de gestação foi formulada para conter: $2.850 \mathrm{kcal} \mathrm{kg-1}$ de energia digestível, $13,28 \%$ de proteína bruta, $0,87 \%$ de cálcio e $0,65 \%$ de fósforo total.

Ração de pré-lactação: 3,0 kg de ração por dia do $86^{\circ}$ ao $107^{\circ}$ e/ ou $110^{\circ}$ dia de gestação. Esta ração foi formulada para conter: $3.150 \mathrm{kcal} \mathrm{kg-1}$ de energia digestível, $13,99 \%$ de proteína bruta, $0,87 \%$ de cálcio e $0,62 \%$ de fósforo total. No período antecedente ao parto (em média cinco dias), os animais receberam $1,5 \mathrm{~kg}$ de ração por dia. Sendo que todos os animais receberam uma dieta-padrão de ração de lactação, formulada para apresentar: $3.450 \mathrm{kcal} \mathrm{kg}$ - 1 de energia digestível, $17,41 \%$ de proteína bruta, $0,88 \%$ de cálcio e $0,65 \%$ de fósforo total. Todos os animais receberam uma dieta formulada com base nas exigências nutri- 
cionais estabelecidas por RostAGNO et al. (2005) para a fase de lactação e sem a adição de antimicrobianos.

Os animais iniciaram o consumo das rações em média cinco dias antes do parto. Essas rações foram fornecidas umedecidas, em quantidade inicial de $3,0 \mathrm{~kg}$ de ração por dia (correspondente ao período pré-parto até os 10 primeiros dias de lactação) e, posteriormente, foram fornecidos $7,5 \mathrm{~kg}$ de ração por dia $\left(11^{\circ}\right.$ ao $21^{\circ}$ dia de lactação), em duas refeições diárias. $\mathrm{O}$ acesso a água foi ad libitum.

Todas as fêmeas parturientes foram assistidas constantemente, tanto durante o parto quanto nos momentos que o precederam. A maioria das parições ocorreu à noite e durante as quintas e sextas-feiras.

Diariamente, todo o plantel de leitões lactantes, no período entre o nascimento e o sétimo dia de vida, foi acompanhado para a verificação e registro de sinais clínicos patológicos, segundo técnica descrita por SCHULZE (1981).

\section{Unidade experimental}

Para compor os grupos experimentais, foram avaliados 1.333 leitões lactentes, machos e fêmeas, com idades entre zero e sete dias de vida, com peso vivo médio inicial ao nascimento de 1,54 $\mathrm{kg} \pm 0,08$.

Os leitões nascidos vivos, após a ingestão do colostro, receberam os manejos de corte e desinfecção do umbigo, corte de cauda e dentes, administração de $2 \mathrm{~mL}$ de ferro dextrano via parenteral e foram submetidos à transferência entre as matrizes somente nas primeiras 24 horas após o parto ou em situações de real necessidade.

Os leitões foram amamentados do nascimento ao desmame aos 21 dias (período médio), mas, a partir do $10^{\circ}$ dia de vida, receberam ração pré-inicial farelada (sem adição de antimicrobiano) e água, ambas ad libitum.

\section{Óleos essenciais}

Os óleos essenciais foram aplicados via oral sob forma de solução de $5 \%$ de óleo essencial de orégano (60\% de cravacrol e 15\% timol - princípios ativos do orégano), $2 \%$ de óleo essencial de alecrim e veículo inerte oleoso. A escolha dos óleos foi determinada através de avaliações in vitro (SANTURIO, 2007) e revisão de bibliografia sobre plantas com alto potencial antimicrobiano, antioxidante e que melhoram a digestibilidade dos nutrientes das dietas.

Optou-se pela utilização dos extratos vegetais sob a forma de óleos essenciais, pois apresentam maior constância na composição, principalmente quando adquiridos de empresa especializada (Givaudan do Brasil Ltda) e com alto controle de qualidade. Os óleos essenciais são extraídos de diversas plantas e são homogeneizados até a obtenção da composição padrão de cada óleo, garantindo, assim, a constância de seus componentes independente da época do ano ou local de extração. Como os óleos essenciais são compostos altamente voláteis, foi necessário submetê-los a um processo chamado de microencapsulamento, que consiste no encapsulamento dos óleos essenciais para que sejam preservados até o momento da ingestão pelos animais. Além disso, esse procedimento também tem como objetivo minimizar o sabor dos óleos na dieta e liberá-los, de forma controlada, no estômago do animal.

\section{Delineamento experimental}

O delineamento experimental foi inteiramente casualizado e composto por dois tratamentos para os parâmetros índice de prevenção e causas de mortalidade dos leitões, correspondendo a:

- Tratamento Controle (T1) - compostos por 661 leitões lactentes sem manifestação clínica de diarreias que receberam solução fisiológica (placebo), 1 $\mathrm{mL} \mathrm{kg}^{-1}$, via oral, no primeiro e terceiro dias de vida. - Tratamento com Óleos Essenciais (T2) - compostos por 672 leitões lactentes sem manifestação clínica de diarreias que receberam, via oral (pigdoser), mescla de óleos essenciais: emulsão liquida a 5\% de óleos essenciais, $1 \mathrm{~mL} \mathrm{~kg}^{-1}$, no primeiro e terceiro dias de vida.

\section{Índice de diarreia}

Para a avaliação do índice de diarreia os leitões foram examinados individualmente, duas vezes ao dia, às 9 e às 18 horas, e realizada também a avaliação visual das fezes, classificadas de um a quatro em líquidas (1); líquidas/pastosas (2); pastosas (3) e sólidas (4). A observação da ocorrência de diarreia foi realizada sempre pelo mesmo observador. Esta consistia em observar por, aproximadamente, 10 minutos os leitões, anotando o número da mossa do(s) animal(s) com diarreia. Observou-se também o piso da baia e, quando havia sinal de diarreia, verificavase entre os animais aquele(s) que tivesse(m) com a região perianal suja de fezes, indicativo de que eles estava(m) com diarreia. Apenas aquelas fezes classificadas como um e dois foram consideradas como diarreicas.

Esta avaliação foi realizada durante a primeira semana de vida dos leitões, visando identificar o início da manifestação da diarreia neonatal e a eficácia do produto. Esta manifestação caracterizava-se por altas morbidade e mortalidade, acometendo desde recém-nascidos até leitões com, aproximadamente, uma semana de idade. Clinicamente, os animais acometidos apresentavam fezes diarreicas de coloração esbranquiçada ou amarelada, apáticos e com baixa taxa de crescimento. 


\section{Análise estatística}

Cada animal representou uma repetição, sendo estas classificadas por grupos de ordem de parição (até 3 , entre 3 e 5 e acima de 5 partos) das fêmeas mães e analisado o efeito da ordem de partos sobre os parâmetros avaliados. Os dados experimentais foram submetidos ao teste de Qui-quadrado com o nível de significância inferior a 0,05\% (VIEIRA, 1983).

\section{RESULTADOS E DISCUSSÃO}

O tratamento administrado não foi efetivo no controlepreventivoda diarreia dosleitões(Tabela1). Esses resultados indicam que as condições experimentais não permitiram observar os possíveis efeitos do uso de mesclas líquidas de óleos essenciais de orégano e alecrim, o que confirma os argumentos de Menten (2001), de que há necessidade de um desafio sanitário suficiente para que os promotores passem a produzir efeitos sobre o desempenho de aves e suínos. O mesmo pode ocorrer se os animais forem alojados em instalações com baixo desafio imunológico e rigoroso controle sanitário (Oetring et al., 2006), como neste experimento, no qual as instalações foram previamente desinfetadas, fechadas e mantidas em vazio sanitário previamente ao alojamento. Assim, os benefícios que poderiam ser obtidos com o uso dos aditivos fitogênicos não foram observados, pois as condições de manejo, ambiente e nutrição foram adequadas para que os leitões expressassem seu potencial. No entanto, a hipótese experimental de que o orégano possui ação antimicrobiana gerou a expectativa de significância na prevenção da diarreia dos leitões que receberam óleo essencial de orégano e alecrim. Segundo Zuanon et al. (1998) e Lima (1999), a ação antimicrobiana dos extratos vegetais sobre a microbiota intestinal pode controlar ou inibir o crescimento dos patógenos e, consequentemente, proporcionar crescimento dos micro-organismos benéficos, favorecendo a prevenção da diarreia e melhorando o desempenho animal.

O fato de não terem ocorrido efeitos significativos entre os tratamentos também poderia ser atribuído ao aspecto da competição patogênica ser insignificante para que os aditivos pudessem interferir nos resultados obtidos. Esta possível explicação é baseada no fato de que os animais foram criados em condições profiláticas boas e com um mínimo de estresse (que normalmente está associado a fatores nutricionais, ambientais ou emocionais), não havendo aumento de bactérias suficiente para causar desequilíbrio na saúde intestinal (FuKAYAMA et al., 2005).

FAIRBROTHER; GyLES (2006) afirmam que as principais causas da diarreia neonatal são a falta de hi- giene e/ ou deficiente desinfecção da cela parideira; atendimento ao parto com as mãos sujas, contaminando a boca do leitão; condições de temperatura baixas ou flutuantes; presença de correntes de ar frio e restrições ou dificuldades para que os leitões mamem o colostro.

Os resultados obtidos identificam-se com os encontrados por UtrYAMA et al. (2006) que, pesquisando os efeitos de probióticos e prebióticos de 500 ppm via ração de extrato vegetal (alho, cravo, canela, pimenta, tomilho, cinamaldeído e eugenol) como alternativas aos agentes antimicrobianos (promotores do crescimento), constataram que nenhum dos tratamentos foi efetivo na prevenção e no controle de diarreias. Entretanto, os resultados discordam daqueles obtidos por Tsinas et al. (1998), quando estes reduziram a incidência de diarreia de 37 para $25 \%$, ao utilizar $250 \mathrm{~g}$ e $500 \mathrm{~g}$, respectivamente, de óleo essencial de orégano por tonelada de ração para suínos com idade entre um dia de vida e o abate.

Os resultados obtidos mostraram ser diferentes dos encontrados por JONGBLOED et al. (2007) que, durante a primeira semana após a inoculação de cepas de E. coli em leitões desmamados e alimentados com dietas contendo extrato de orégano, revelaram um escore da consistência fecal dos animais significativamente maior comparado ao grupo de leitões controle negativo $(\mathrm{P}<0,05)$. Assim, estes pesquisadores constataram que um aditivo fitogênico à base de orégano controla a proliferação $E$. coli e melhora a consistência fecal dos leitões desmamados. No entanto, OetTing et al. (2006) também não encontraram diferença significativa na frequência de diarreia de leitões desmamados quando alimentados com dieta contendo 700, 1.400 e 2.100 ppm de extratos vegetais de orégano e tomilho (com a adição de carvacrol 3,33\%) cravo (com a adição de eugenol $3,33 \%)$, respectivamente.

Os resultados experimentais revelam que a ordem de parto inferior a três, entre 3 e 5 e superior a 5 das fêmeas suínas, apresenta influência significativa sobre o índice de diarreia neonatal dos leitões, independentemente dos tratamentos aplicados e do controle sintomatológico da diarreia na primeira semana de vida dos leitões, podendo este resultado estar vinculado à eficiência imunitária das fêmeas suínas (Tabela 1 ).

Machado Neto et al. (2001) observoram que fêmeas de primeira cria apresentaram menor concentração de imunoglobulina $\mathrm{G}\left(49,98 \pm 7,9 \mathrm{mg} \mathrm{mL}^{-1}\right) \mathrm{em}$ relação às fêmeas de segunda $\left(92,70 \pm 5,9 \mathrm{mg} \mathrm{mL}^{-1}\right)$, terceira $\left(70,72 \pm 5,6 \mathrm{mg} \mathrm{mL}^{-1}\right)$ e quarta crias $(85,56 \pm$ $\left.9,0 \mathrm{mg} \mathrm{mL}^{-1}\right)$, evidenciando que fêmeas suínas com maior experiência imunológica apresentam maior concentração de imunoglobulina no colostro e, por meio disto, maior percentual de leitões sem sinais clínicos de diarreia neonatal. 
Tabela 1 - Índice de prevenção da diarreia neonatal em leitões conforme os tratamentos e as ordens de partos das fêmeas suínas.

\begin{tabular}{|c|c|c|c|c|c|}
\hline Tratamentos & $\mathrm{OP}$ & NLP/TL & $\%$ PLDN & $\mathrm{X}^{2}$ & $\mathrm{P}$ \\
\hline \multirow{3}{*}{ Controle } & $<3$ & $72 / 129$ & $55,81^{c}$ & \multirow{3}{*}{43,893} & \multirow{3}{*}{$<, 0001$} \\
\hline & 3 a 5 & $129 / 175$ & $73,71^{\mathrm{b}}$ & & \\
\hline & $>5$ & $302 / 357$ & $84,59^{a}$ & & \\
\hline \multirow{3}{*}{ Óleos essenciais } & $<3$ & $78 / 133$ & $58,65^{c}$ & \multirow{3}{*}{54,87} & \multirow{3}{*}{$<, 0001$} \\
\hline & 3 a 5 & $143 / 177$ & $80,79^{b}$ & & \\
\hline & $>5$ & $320 / 362$ & $88,4^{\mathrm{a}}$ & & \\
\hline
\end{tabular}

NLP - Número de leitões prevenidos da diarreia neonatal após o tratamento;

PLDN - Prevenção da diarreia neonatal de leitões;

TL - Total de leitões em cada grupo;

$X^{2}$ - Teste do Qui Quadrado;

OP- Ordem de parto da fêmea suína;

$a, b$ - Letras diferentes são estatisticamente significantes $(P<0,0001)$;

$\mathrm{P}-(\mathrm{P}<0,0001)$.

\section{CONCLUSÃO}

Os resultados alcançados com uso de óleos essências, nas doses de $1 \mathrm{~mL} \mathrm{~kg}^{-1}$, administradas via oral para leitões entre o primeiro e o terceiro dias de vida, permitem concluir que o os óleos essências de orégano e alecrim não previnem as diarreias neonatais dos leitões.

Este estudo foi desenvolvido de acordo com as normas do COBEA (Colégio Brasileiro de Experimentação Animal). O projeto foi aprovado pela Comissão de Ética e Biossegurança da Universidade Federal de SantaMaria,UFSM-RS, sobon. 23081.006656/2009-25.

\section{REFERÊNCIAS}

ANAMI, M.R.; SANTOS, G.M.J. dos; FERREIRA, R.S. Desenvolvimento e avaliação de uma bacterina contra colibacilose em Suínos. Iniciação Científica CESUMAR, v.10, n.2, p135-140, 2008.

BELLAVER, C.O uso de microingredientes (aditivos) na formulação de dietas para suínos e suas implicações na produção e na segurança alimentar. In: CONGRESSO MERCOSUR DE PRODUCCIÓN PORCINA, 2000, Buenos Aires. Anales. Bueno Aires: Facultad de Ciencias Veterinarias da Universidad de Buenos Aires, Universidad Nacional de Rio Cuarto e Embrapa Suinos e Aves, 2000. p.93-108.

BRITO, B.G.; FILIPPSEN, L.F.; MORES, N.; BRENTANO, L.; BRITO, M.A.V.P. Etiologia da diarréia de leitões lactantes em granjas suinícolas do sudoeste do Paraná. Semina, v.16, n.1, p.7-13, 1995.

BRUGALI, I. Alimentação alternativa: a utilização de fitoterápicos ou nutracêuticos como moduladores da imunidade e desempenho animal. In: SIMPÓSIO
SOBRE MANEJO E NUTRIÇÃO DE AVES E SUÍNOS, 2003, Campinas. Anais. Campinas: Colégio Brasileiro de Nutrição Animal, 2003. p.167-182.

DEMATTÊ, L.C.F. Aditivos em dietas de frangos de corte criados em sistema alternativo. 2004. 86f. Dissertação (Mestrado) - Universidade Estadual Paulista, Botucatu, 2004.

DEWEY, C.E.; WITTUM, T.E.; SCOTT, H.H.; DARGATZ, D.A.; HILL, G.W. Herd and litter-level factors associated with the incidence of diarrhea morbidity and mortality in piglets 4-14 days of age. Swine Health Products, v.3, p.21-28, 1995.

FAIRBROTHER, J.M.; GYLES, C.L. E. coli infections. In: STRAW, B.E.; ZIMMERMAN, J.J.; D'ALLAIRE, S.; TAYLOR, D.J. Diseases of swine. 9 ed. Ames: Blackwell Publishing, 2006. p.639-664.

FIREMAN, F.A.T.; SIEWERDT, F. Efeito sazonal sobre a natimortalidade e mortalidade de leitões até 21 dias de idade. Ciência Rural, v.27, n.3, p.479-483, 1997.

FUKAYAMA, E.H.; BERTECHINI, G.A.; GERALDO, A.; KATO, K.R.; MURGAS, S.D.L. Extrato de orégano como aditivo em rações para frangos de corte. Revista Brasileira Zootecnia, v.34, n.6, p.2316-2326, 2005.

HERNANDEZ, F.; MADRID, J.; GARCIA, V.; ORENGO, J.; MEGIAS, D.M. Influence of two plant extracts on broilers performance, digestibility, and digestive organ size. Poultry Science, v.83, n.2, p.169-174, 2004.

HOLLAND, R.E. Some infectious causes of diarrhea in young farm animals. Clinical Microbiology Reviews, v.3, n.4, p.345-375, 1990.

JIN, L.Z.; HO, Y.W.; ZHAO, X. Probiotics in poultry: modes of action. World's Poutry Science Journal, v.53, p.351-368, 1997. 
JONGBLOED, A.W.; MAIORANO, R.; WAGENAARS, C.M.F. Effect of several plant products on prevention of E. coli adhesion in the gastrointestinal tract of weaned piglets. Animal Sciences Group, v.62, p.1-22, 2007.

KAMEL, C. A novel look at a classic approach of plant extracts. Feed Mix, v.9, n.2, p.19-24, 2000.

KATSUDA. K.; KOHMOTO M.; KAWASHIMA, K.; TSUNEMITSU, H. Frequency of enteropathogen detection in suckling and weaned pigs with diarrhea in Japan. Journal of Veterinary Diagnostic Investigation, v.18, n.4, p.350-354, 2006.

LIMA, G.J.M.M. Uso de aditivos na produção de suínos. In: SIMPÓSIO SOBRE AS IMPLICAÇÕES SÓCIO-ECONÔMICAS DO USO DE ADITIVOS NA PRODUÇÃO ANIMAL, 1999, Piracicaba. Anais. Piracicaba: Universidade Metodista de Piracicaba, 1999. p.51-68.

MACARI, M.; MAIORKA, A. Função gastrintestinal e seu impacto no rendimento avícola. In: CONFERÊNCIA APINCO 2000 DECIÊNCIA E TECNOLOGIA AVÍCOLAS, 2000, Campinas. Anais. Campinas: Fundação Apinco de Ciência e Tecnologia Avícolas, 2000. p.1.61-174.

MACHADO NETO, M.R.; PACKER, I.U.; MENTEN, J.F.; LAVORENTI, A. Efeito da raça, dieta, época e ordem de parição na concentração de imunoglobulina $\mathrm{G}$ no colostro de suínos. Pesquisa Agropecuaria Brasileira, v.36, n.10, p.12951299, 2001.

MARTINEAU, G.P.; VAILLANCOURT, J.P.; BROES, A. Principal neonatal diseases. In: VARLEY, M.A. (Ed.). The neonatal pig development and survival. Québec: CAB International, 1995. p.239-268.

MELLOR, S. Herbs and spices promote health and growth. Pig Progress, v.16, n.4, 2000.

MENTEN, J.F.M. Aditivos alternativos na nutrição de aves: probióticos e prebióticos. In: REUNIÃO ANUAL DA SOCIEDADE BRASILEIRA DE ZOOTECNIA, 38., 2001, Piracicaba. Anais. Piracicaba: Sociedade Brasileira de Zootecnia/Sonopress, 2001. 1-CD-ROM.

NATIONAL RESEARCH COUNCIL (US). Nutrient requeriments of swine. 10.ed. Washington, D.C.: National Academy Press, 1998. 189p.

OETTING, L.L.; UTIYAMA, E.C.; GIANI, A.P.; RUIZ, S.U. dos; MIYADA, S.V. Efeitos de extratos vegetais e antimicrobianos sobre a digestibilidade aparente, $\mathrm{o}$ desempenho, a morfometria dos órgãos e a histologia intstinal de leitões recém-desmamados. Revista Brasileira de Zootecnia, v.35, n.4, p.1389-1397, 2006

SCHULZE, W. Physical examination. In: LEMAN, A.D., GLOCK, R.D., MENGELING, W.L.; PENNY, R.H.C.; SCHOLL, E.;STRAW, B. Diseases of swine. 5.ed. Ames: Iowa State University, 1981. Cap.64, p.686-695.

ROSTAGNO, H.S., ALBINO, L.F.T., DONZELE, J.L. Tabelas brasileiras para aves e suínos: composição de alimentos e exigências nutricionais. 2.ed. Viçosa: Universidade Federal de Viçosa, 2005.

SANTURIO, J.M.; SANTURIO, D.F.; POZZATTI, P.; MORAES, C.; FRANCHIN, P.R.; ALVES, S.H., Atividade antimicrobiana dos óleos essenciais de orégano, tomilho e canela frente a sorovares de Salmonella enterica de origem avícola. Ciência Rural, v.37, n.3, p.803-808, 2007.

SIMÕES, C.M.O.; SPITZER, V. Óleos voláteis. In: SIMÕES, C.M.O.; SCHENKEL P.E.; GOSMANN, G.; MELLO, P.C.J. de; MENTZ, A.L.; ROS PETROVICK, P. Farmacognosia: da planta ao medicamento. Porto Alegre: UFRGS, 1999. Cap.18, p.387-416.

TSINAS, A.C.; GIANNAKOPOULOS, C.G.; PAPASTERIADES, A.; ALEXOPOULOS, C.; MAVROMATIS, J.; KYRIAKIS, S.C. Use of origanum essential oils as growth promoters in pigs. In: INTERNATIONAL PIG VETERINARY SOCIETY CONGRESS, 15., 1998, Birmingham, England. Proceedings. Birmingham, 1998. v.3, p.216-221.

UTIYAMA, C.E. OETTING, L.L.; GIANI, A.P.; RUIZ, S.U. dos; MIYADA, S.V. Efeitos de antimicrobianos, prebióticos, probióticos e extratos vegetais sobre a microbiota intestinal, a freqüência de diarréia e o desempenho de leitões recém-desmamados. Revista Brasileira de Zootecnia, v.35, n.6, p.2359-2367, 2006.

VIEIRA, S. Introdução a bioestatística. 2.ed. Rio de Janeiro: Ed. Campus, 1983.

ZUANON, J.A.S.; FONSECA, J.B.; ROSTAGNO, H.S.; SILVA, M.A. Efeito de promotores de crescimento sobre o desempenho de frangos de corte. Revista Brasileira de Zootecnia, Viçosa, v.27, n.5, p.999-1005, 1998.

Recebido em $17 / 2 / 10$

Aceito em 30/12/10 